\title{
Clay-biochar composite for arsenic removal from aqueous media
}

\author{
M. Vithanage ${ }^{1}$, L. Sandaruwan ${ }^{2}$, G. Samarasinghe ${ }^{2}$ \& Y. Jayawardhana ${ }^{3}$ \\ ${ }^{1}$ Faculty of Applied Science, University of Sri Jayewardenepura, Nugegoda, Sri Lanka \\ ${ }^{2} S$. de S. Jayasinghe Central College, Dehiwala, Sri Lanka \\ ${ }^{3}$ Environmental Chemodynamics Project, National Institute of Fundamental Studies, Kandy, Sri Lanka
}

\begin{abstract}
Arsenic is present mainly in groundwater in the forms of highly toxic arsenate and arsenite. Biochar has been a promising cost effective and carbon negative material for many different contaminants such as trace metals, antibiotics, pesticides etc., however, not for anionic metalloids as arsenic. This study intended to evaluate the potential of a novel composite prepared using biochar, derives from fibrous fraction of municipal solid waste in Gohagoda landfill site, Kandy, Sri Lanka and red earth clay for remediate As(III) in aqueous media. Pyrolyzed biochar+red earth composite was characterized for its physicochemical properties. Furthermore, As(III) pH dependency ( $\mathrm{pH} 3-9)$, kinetics behavior and sorbate (50-1000 $\mu \mathrm{g} \mathrm{L}^{-1}$ ) concentrations were investigated using a batch sorption technique. The concentrations of As(III) in aqueous media were measured by inductively coupled plasma optical emission spectrometry. For arsenic (III), pH 6-7 range was favorable for adsorption process. Whereas, highest adsorption at 24 hours reaction time at $\mathrm{pH} 6-7$ recorded as around $25 \%$ $\left(12.5 \mu \mathrm{g} \mathrm{g}^{-1}\right)$ for arsenic (III). Moreover, well fitted pseudo second order $\left(\mathrm{R}^{2}=0.928\right)$ could suggest chemical adsorption mechanism rather than a physical adsorption mechanism in to the adsorbent. Hence, process involved with chemisorption can be suggested as the As(III) removal mechanism. However, further isotherm experiments are needed with expanded concentration range to mechanism identification.
\end{abstract}

\section{INTRODUCTION}

Presence of arsenic in water sources has been a serious concern worldwide. Arsenic is present mainly in groundwater in the forms of highly toxic inorganic forms of arsenate and arsenite. Literature reveals that many techniques have been examined for arsenic removal from water. The most commonly used methods include coagulation with iron and aluminum salts; ion-exchange, reverse osmosis and electro-dialysis; adsorption onto activated alumina/carbon, activated bauxite, clay minerals and iron oxides (Nicomel et al., 2016). Most of the methods are expensive and labor intense, which hinder the application in community scale whereas the chemical methods yield large quantities of solid sludge, which demands further treatment. Since adsorption process is simple, easy to handle and being regenerable, it has been widely used to remove arsenic (Duan et al., 2017).

Biochar (BC) has been widely examined as adsorbent for removal of containments such as heavy metals and organic compounds in water and soil has also been reported (Ahmad et al., 2014). As many waste materials can be used to produce biochar, there has been a great interest in using municipal solid waste as a feedstock thus supportive in reducing waste quantities (Jayawardhana et al., 2017). However, its capacities for anionic metalloid removal have been low rendering it suitable for arsenic removal application (Vithanage et al., 2017).

Clay has been widely used in arsenic removal whereas Natural Red Earth (NRE) exhibited excellent performances for both $\mathrm{As}(\mathrm{III})$ and $\mathrm{As}(\mathrm{V})$ removal at the same instance without any environmental change (Vithanage et al., 2006, 2007). Hence, this study intended to evaluate the potential of a novel clay$\mathrm{BC}$ composite prepared using biochar, derives from fibrous fraction of municipal solid waste in Gohagoda landfill site, Kandy, Sri Lanka and red earth clay for remediate As in aqueous media.

\section{METHODS}

\subsection{Feedstock for biochar and natural red earth}

The segregated organic fraction of the municipal solid waste (MSW) obtained from dump site Gohagoda, Kandy, Sri Lanka. Natural red earth (NRE) was obtained from the limestone quarry of the Aruwakkalu, Sri Lanka.

\subsection{Composite preparation}

Stable clay suspensions of MT and/or RE were prepared separately ( $50 \mathrm{~g}$ clay in $2 \mathrm{~L}$ deionized (DI) water) 


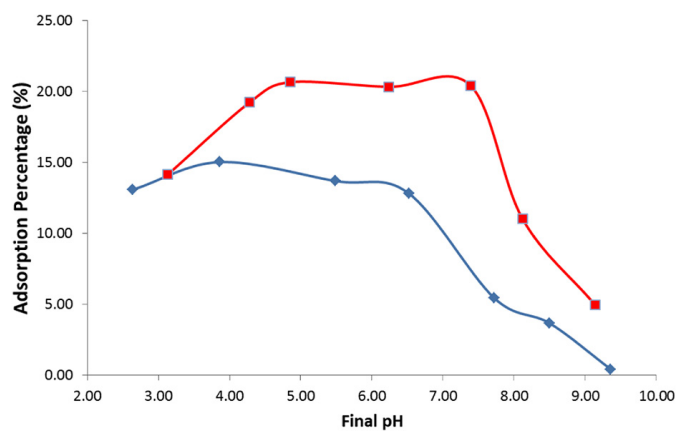

Figure 1. Arsenic (III) and (V) sorption to clay-BC composite at $2 \mathrm{~g} \mathrm{~L}^{-1}$. Arsenic (III) in square shape symbols whereas arsenic (V) in diamond symbols.

followed by sonication of the mixture for 30 minutes in an ultrasonicator. Then $250 \mathrm{~g}$ of MSW biochars were added to clay suspensions and the mixtures were shaken for 2 hours. The clay-biochar suspensions were filtered and BC-clay feedstocks were oven dried at $80^{\circ} \mathrm{C}$ in an oven overnight. The clay treated biomass feedstocks were packed tightly into ceramic crucibles and slow pyrolysis was done at a rate of $7^{\circ} \mathrm{C} \mathrm{min}^{-1}$ under oxygen limited conditions in a muffle furnace (MTI, Richmond, CA). The pyrolysis temperature was increased to $500^{\circ} \mathrm{C}$ and held constant at $500^{\circ} \mathrm{C}$ for 30 minutes. Untreated MSW feedstock was also pyrolyzed under same pyrolysis conditions. All the biochar samples were washed with DI water several times to remove impurities, dried in an oven at $80^{\circ} \mathrm{C}$ and sealed in a container for further testing.

\subsection{Batch experiments}

The effect of $\mathrm{pH}$ on the sorption was studied by adjusting the $\mathrm{pH}$ in the range of 3-9. The adsorbent concentration was kept at $2.00 \mathrm{~g} \mathrm{~L}^{-1}$ of solution containing $125 \mu \mathrm{g} \mathrm{L}^{-1}$ As at $25^{\circ} \mathrm{C}$ for overnight. The kinetics experiments were conducted for $24 \mathrm{~h}$ at the same concentrations of sorbents and sorbate. The samples were then filtered using $0.45 \mu \mathrm{m}$ PVDF disposable filters and As concentrations in the solutions were measured by the inductive coupled plasma optical emission spectroscopy (ICP-OES, Thermo).

\section{RESULTS AND DISCUSSION}

For As(III), pH 6-7 range was favorable for adsorption process (Fig. 1). The highest adsorption at 24 hours reaction time at $\mathrm{pH} 6-7$ recorded as around $25 \%$ (12.5 $\left.\mu \mathrm{g} \mathrm{g}^{-1}\right)$ for $\mathrm{As}(\mathrm{III})$.
Arsenic (III) kinetic data exhibited no equilibrium at $24 \mathrm{~h}$ at $150 \mu \mathrm{g} \mathrm{L}^{-1}$. However, the data were well fitted to pseudo second order $\left(\mathrm{R}^{2}=0.928\right)$ could suggest chemical adsorption mechanism rather than a physical adsorption mechanism in to the adsorbent.

\section{CONCLUSIONS}

The Clay-BC composite indicated high removal of arsenic from water at environmental $\mathrm{pH}$ conditions with strong chemisorption interactions. Further, arsenic removal to be investigated for sorbent concentrations and column experiments.

\section{ACKNOWLEDGEMENTS}

Chairperson, Director and the Science Popularization Division of the National Science Foundation, Sri Lanka and Principal, S. de S. Jayasinghe College are acknowledged for the support.

\section{REFERENCES}

Ahmad, M., Rajapaksha, A.U., Lim, J.E., Zhang, M., Bolan, N., Mohan, D., Vithanage, M., Lee, S.S. \& Ok, Y.S. 2014. Biochar as a sorbent for contaminant management in soil and water: a review. Chemosphere 99: 19-33.

Duan, X., Zhang, C., Srinivasakannan, C. \& Wang, X. 2017. Waste walnut shell valorization to iron loaded biochar and its application to arsenic removal. Res-Efficient Technol. 3(1): 29-36.

Jayawardhana, Y., Mayakaduwa, S., Kumarathilaka, P., Gamage, S. \& Vithanage, M. 2017. Municipal solid wastederived biochar for the removal of benzene from landfill leachate. Environ. Geochem. Hlth.: 1-15.

Nicomel, N.R., Leus, K., Folens, K., Van Der Voort, P. \& Du Laing, G. 2015. Technologies for arsenic removal from water: current status and future perspectives. Int. $J$. Environ. Res. Public Health 13(1): 62.

Vithanage, M., Chandrajith, R., Bandara, A. \& Weerasooriya, R. 2006. Mechanistic modeling of arsenic retention on natural red earth in simulated environmental systems. $J$. Colloid Interface Sci. 294(2): 265-272.

Vithanage, M., Herath, I., Joseph, S., Bundschuh, J., Bolan, N., Ok, Y.S., Kirkham, M. \& Rinklebe, J. 2017. Interaction of arsenic with biochar in soil and water: a critical review. Carbon 113: 219-230.

Vithanage, M., Senevirathna, W., Chandrajith, R. \& Weerasooriya., R. 2007. Arsenic binding mechanisms on natural red earth: a potential substrate for pollution control. Sci. Total Environ. 379(2-3): 244-248. 